\title{
Conception, gestation, and birth of a journal: the future of genetics in medicine includes Genetics in Medicine
}

The first act of a president of any organization is to accept the responsibilities of the office. The last act is to say "Thank you." In between, the president is a servant of the membership. I trust that this first issue of Genetics in Medicine proves to be satisfactory to both the membership of the American College of Medical Genetics and the broader genetics community, and that this new journal will serve as partial testimony to my stewardship of the College.

My first major responsibility for the College, just after its incorporation, was chairing the Publication Committee. In 1992, the Board of Directors endorsed the notion of an official journal. Prolonged, often tortuous negotiations with publishers about merging our interests with existing journals or starting a new one proved fruitless. One of our early contacts was the Baltimore-based publisher, Lippincott Williams \& Wilkins. After a considerable hiatus, we re-established negotiations in 1996 and progress was rapid and gratifying. From the start of serious discussions to the appearance of this first issue of Genetics in Medicine has taken exactly two years. The efficiency and proficiency of this process are testimonies to our Editor-in-Chief, Richard King, and the publisher. To be sure, a few members of the College have voiced concern all along the way about initiating a journal. Although the rationale of the Board of Directors is described well by Dr. King in his accompanying editorial, it is the quality and utility of this product that should prove convincing.

One benefit of presiding over the College for the past two years has been the opportunity to work with the leaders of other professional societies, with governmental officials and policy makers, and with con- sumers and volunteer support organizations. There is considerable and growing acknowledgment of the relevance of medical genetics as a specialty, but more generally, of the importance of genetics in society. A brief snapshot of my life is instructive. This past weekend I participated in two conferences, one addressing interfaces among ethics, genetics, and the law, and the other considering how to implement prenatal screening for cystic fibrosis heterozygosity. Yesterday, a medical specialty society requested the advice of the College in designing patient brochures about hereditary susceptibilities to common disease. The day before, another society asked us to review their draft of practice guidelines for a specific genetic condition. Literally (and I am not making this up) as I write this, I am listening to a story on National Public Radio about the potential for "stereotyping by genotyping" in the workplace. The College recently contacted federal legislators urging them to expedite consideration of prohibitions of unfair discrimination based on genetic information.

The American College of Medical Genetics and its members must seize leadership roles in a wide variety of educational, policy, service, and research activities. Genetics in Medicine will be a valuable instrument in our work. This journal has been established to bring favorable notice to us, but first we must strive to bring credit to it.

Reed Edwin Pyeritz, MD, PhD President, American College of Medical Genetics 